\title{
LUGARES DE MEMORIA: \\ ENTRE LA TENSIÓN, LA PARTICIPACIÓN Y LA REFLEXIÓN
}

\section{Places of memory: between tension, participation and reflection}

Lugares de memória: entre a tensão, a participação e a reflexão.

RECIBIDO: 12 DE MARZO DE 2013

Yaneth Mora Hernández (Colombia)

Universidad de Barcelona

yanethmorah@gmail.com

Historiadora, licenciada en Ciencias Sociales y candidata a magíster en Gestión del

Patrimonio Cultural.
EVALUADO:3 DE MAYO DE 2013
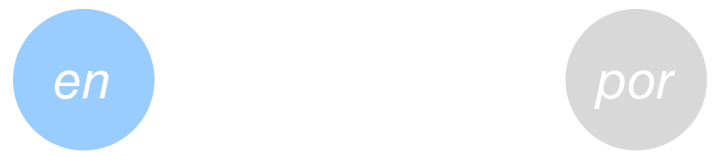

\section{RESUMEN}

Los lugares de memoria reflejan las reflexiones que hacen determinadas sociedades sobre su pasado y las forma como este es representado. Estos lugares están atravesados por un conjunto de tensiones políticas e ideológicas que determinan qué se recuerda y qué se olvida y en función de qué recordamos. Museos, centros de memoria y monumentos conmemorativos son los espacios que han permitido territorializar la memoria y hacer del pasado reciente un documento vivo para el aprendizaje y la reflexión. Estos lugares han sido posibles gracias al trabajo colectivo, sistemático y concienzudo de organizaciones de víctimas y derechos humanos, quienes desde su accionar han permitido que las lecciones del pasado guíen nuestro presente $\mathrm{y}$ futuro.

PALABRAS CLAVE: Memoria, lugares de memoria, espacio público, patrimonio.

\section{ABSTRACT}

The places of memory reflect the thoughts that certain societies make about their past and how this is represented. These places are cut by a set of political and ideological tensions that determine what is remembered and what is forgotten and depending on what we remember. Museums, memory centers and memorials are the spaces that have allowed us to localize the memory and turn the recent past into a living document for learning and reflection. These places have been possible thanks to the collective, systematic and conscientious work of victims and human rights organizations, who, from their actions, have allowed the lessons of the past to guide our present and future.
KEYWORDS: Memory, memory places, public space, heritage.

\section{ACEPTADO:3 DE MAYO DE 2013}

\section{RESUMO}

Os lugares de memória refletem as reflexões que fazem determinadas sociedades sobre o seu passado e as formas como este é representado. Estes lugares estão atravessados por um conjunto de tensões políticas e ideológicas que determinam o que se lembra e o que se esquece e em função do que lembramos. Museus, centros de memória e monumentos comemorativos são os espaços que têm permitido territorializar a memória e fazer do passado recente um documento vivo para o aprendizado e a reflexão. Estes lugares têm sido possíveis graças ao trabalho coletivo, sistemático e feito com muita atenção e detalhe, de organizações de vítimas e direitos humanos, quem desde o seu acionar têm permitido que as lições do passado guiem o nosso presente e o futuro.
PalaVRAS CHAVE: Memória, lugares de memória, espaço público, patrimônio.

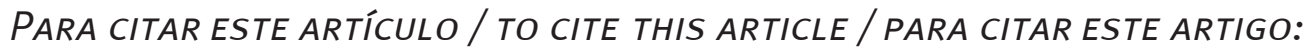



El concepto de patrimonio cultural es subjetivo, dinámico y no depende de los objetos o bienes, sino de la puesta en valor que la sociedad les atribuye, por lo que determina qué debemos proteger y conservar para la posteridad. La lectura del patrimonio abarca, además de la descripción histórica o tipológica de los objetos o bienes, sus significados y función social. Por eso, la busqueda de elementos simbólicos, de significación politica e identitaria, así como el trabajo del dolor, el duelo, el conflicto y el olvido, constituyen nuevas dimensiones de un patrimonio ligado al pasado y a su memoria (Guixé, 2009). En este sentido, una de las manifestaciones que como sociedad estamos llamados a valorar y salvaguardar son los lugares de memoria que hacen parte y se circunscriben en el patrimonio memorial.

Pierre Nora (2009) define como lugares de memoria no solo a los monumentos, espacios, paisajes u objetos, sino también a las fiestas, los emblemas, las conmemoraciones, los cantos, etcétera; en definitiva, todas las representaciones materiales o simbólicas portadoras de memoria. Su función en cuanto patrimonio memorial es la transformacion de la memoria del pasado en una cuestion crítica del presente gracias a un ejercicio colectivo de reflexión. Estos lugares de memoria, que también son de comunicación y difusión, nos llevan a una toma de conciencia basada no en las sombras del olvido, sino en la necesidad de reflexión (Guixé, 2009).

Ahora bien, los lugares de memoria reflejan los debates y discusiones alrededor de la historia y memoria en cada sociedad. Con estas manifestaciones espaciales es posible leer en qué estado se encuentra la memoria en una sociedad dada y los actores, conflictos y aspiraciones que la animan. El espacio público y las manifestaciones memorialísticas que en este se alojan reflejan qué tan importante ha sido esta problemática, si ha habido o no políticas de memoria o si existe voluntad tanto de la sociedad civil como del Estado.

Las tensiones políticas e ideológicas que revisten los lugares de memoria afloran dentro de la sociedad cuando esta ha atravesado por conflictos internos que han generado rupturas y divisiones. La gestión de una memoria colectiva atravesada por conflictos políticos está caracterizada por los deseos de recordar y olvidar, arraigados en el espacio público. Las tensiones entre lo que se quiere recordar y lo que se quiere olvidar se manifiestan en los espacios de memoria y, por tanto, son estos territorios los que están constantemente siendo objeto de disputas y tensiones. Qué recordar y qué olvidar y cómo representarlo en el espacio ha sido y seguirá siendo un campo de batalla ideológico y político.

La construcción de la memoria social ha venido planteando como elemento consustancial su emplazamiento de espacios significativos en los ámbitos urbanos. Los espacios públicos se han venido invistiendo de nuevas significaciones y, en este sentido, la memoria social va requiriendo de lugares donde el recuerdo y la conmemoración se circunscriban a un espacio físico. La memoria territorializada ayuda a revisar cómo esta ha sido narrada y cómo esa narración se materializa en el espacio público y en la construcción de ciudadanía. Esto permite que los lugares de memoria enclavados en un territorio determinado no permanezcan inmóviles ni estáticos, sino que se encuentren en movimiento y en un proceso de constante resignificación (Escobar y Fabri, 2009).

En los últimos años, gracias a la irrupción de un conjunto de políticas de la memoria en diferentes países, han venido surgiendo y consolidándose lugares de memoria que bien pueden estar representados en museos, memoriales, cementerios, conmemoraciones y demás manifestaciones. Estos espacios de memoria han venido trabajando en la generación de acciones educativas que permiten, además de dignificar a las víctimas de las diferentes violaciones a los derechos humanos, explicar a las nuevas generaciones el pasado inmediato y los costes históricos y humanos que tuvo la lucha por la democracia.

| Panorama
| pp. 97 - 109
| Volumen 7
| Número 13
| Julio - diciembre | 2013 
Museos o centros de la memoria y monumentos conmemorativos materializan territorialmente la memoria social. Este vínculo de la memoria con el territorio se transforma en un enclave político en el que el recuerdo y el olvido, la conmemoración o el homenaje se convierten en el resultado de una construcción social, cultural y política. Así mismo, los procesos de lugarización de la memoria ponen de relieve la importancia de construcción de sentido de espacios que otrora tuvieron otros usos o significaciones y que ahora, gracias a políticas de memoria producto de las reivindicaciones ciudadanas, cobran nuevos sentidos a partir de la implementación de dichas políticas públicas.

Un estudio de víctimas de la violencia sugirió que — después de la compensación financiera - las iniciativas de memorialización eran la segunda forma de reparación más importante procedente del Estado. Usando estrategias explícitas, los monumentos conmemorativos públicos y los museos o centros de la memoria pueden contribuir en el largo plazo a la construcción de culturas democráticas más amplias, al generar diálogos entre diferentes comunidades o hacer partícipes a las nuevas generaciones de las lecciones aprendidas del pasado (Brett, Bickford, Ševcenko y Ríos, 2009). Enfrentar el pasado conflictivo es un componente esencial de la construcción de una identidad nacional basada en los derechos y la dignidad humana, y por tanto la construcción de estos escenarios son un aporte significativo a la reconstrucción de una sociedad devastada.

\section{MUSEOS DE LA MEMORLA: ROMPIENDO LOS ESQUEMAS TRADICIONALES}

Los museos de la memoria se constituyen en un tipo de museos que se han venido desarrollando en el centro de la sociedad contemporánea, en el marco de tensiones políticas que han generado inusitados conflictos sociales. Según Loreto y López (2005), hasta finalizada la Segunda Guerra Mundial se observa el desarrollo sistemático de un tipo de museos que busca rescatar y exhibir la experiencia de un hecho considerado excepcional y emblemático. Puede decirse que el holocausto es el origen de una camada de museos donde la memoria de los sobrevivientes constituye una fuente fundamental para la organización de un relato sobre el pasado reciente.

Tal como el holocausto, otros momentos históricos que han generado fracturas al interior de la sociedad, ya sea por tratarse de represión, persecución, exterminio o discriminación, han originado museos dedicados a provocar un efecto de recordación que impida el olvido de aquellos hechos y que construya una interpretación comprensiva de los estos mismos. Guerras, revoluciones, dictaduras, segregación racial, genocidios, etnocidios y otras experiencias entendidas como crímenes de lesa humanidad se encuentran entre los casos que ocupan a los museos o centros de la memoria.

Este tipo de lugares de memoria territorializada proporcionan una visión del pasado siempre ligada a la problematización del presente, a la vez que trascienden ciertas formas tradicionales como los monumentos conmemorativos. E1 presente está vinculado de manera directa con las narrativas de los museos o centros de la memoria, en cuanto es en función del presente y el futuro que este tipo de escenarios trabajan, buscando formar una conciencia política fuerte que defienda valores democráticos y construya ciudadanía.

Panorama | pp. $97-109$ | Volumen 7 | Número 13 |

Los museos y centros de la memoria materializan y responden a una nueva concepción de museos vinculados a los intereses y necesidades de la comunidad. Estos espacios han dejado de estar aislados y ajenos a la problemática de la población, generando un proceso de concientización y apropiación de sus historias particulares. Para estos museos insertos dentro de la nueva museología, la relación tricategorial compuesta por territorio, patrimonio y comunidad supera la concepción tradicional que define al museo con base en un edificio, una colección y un público. En estos espacios es consustancial la participación comunitaria en torno a su patrimonio cultural, donde se den espacios de reflexión crítica del colectivo social y dichas reflexiones generen cambios tangibles. Un museo vivo para el presente y el futuro, que aprende de las lecciones del pasado y hace parte y relata los cambios de la sociedad en la que está inserto, sintetiza los museos de la memoria. 
Ahora bien, la proliferación de los museos y centros de la memoria en las últimas décadas ha sido producto de un conjunto de circunstancias históricas e ideológicas que han permitido repensar el papel de estos espacios. Estas circunstancias podrían sintetizarse así:

- El concepto de patrimonio de la nueva museología. La nueva museología plantea concepciones renovadas alrededor del patrimonio y el papel de los museos. Esta corriente museológica plantea un análisis sistemático de la realidad museal basado en la prioridad de las personas o comunidades sobre el objeto dentro del museo y en la consideración del patrimonio como un instrumento al servicio del desarrollo de la sociedad. Estos nuevos conceptos de patrimonio y museo generan cambios en el tipo de espacios museales que se crean. De allí que los museos de la memoria estén más vinculados con un patrimonio que está al servicio del desarrollo de la comunidad en que se inserta. La memoria como proceso complejo y de construcción colectiva no podría haberse concebido dentro de una museología tradicional.

- Fortalecimiento de las políticas públicas de la memoria y surgimiento de leyes de memoria histórica. Este tipo de políticas y leyes se han venido presentando en sociedades en situaciones de postconflicto que han avanzado hacia la democracia. Con estas leyes se están generando espacios de memoria que permiten la consolidación y robustecimiento de derechos políticos. El papel de los gobiernos y de la sociedad civil ha sido clave en el fortalecimiento de políticas públicas, ya que es a partir de un trabajo conjunto que los monumentos conmemorativos y centros o museos de memoria adquieren legitimidad.

- Trabajo permanente de defensa de los derechos humanos. Los museos y centros de la memoria han sido posibles gracias al trabajo constante, sistemático y arduo que han venido desarrollando organizaciones y colectivos de derechos humanos. La presión por el esclarecimiento de la verdad, la justicia y la reparación, así sea simbólica, ha generado muchas iniciativas donde los monumentos conmemorativos y museos de la memoria tienen lugar. Estos museos y centros de memoria a su vez han podido constituirse en nuevos espacios para una participación ciudadana abierta y perdurable.

En síntesis, el establecimiento de museos y centros de la memoria responde a un contexto histórico y político de construcción de sociedades democráticas que buscan la consolidación de identidades por medio de la participación colectiva. Estos espacios buscan realizar una reconstrucción simbólica del pasado y, en esa medida, se ocupan de subsanar la violencia cultural y contribuir a la construcción de una cultura de paz.

Aun así, es importante destacar que los museos o centros de memoria no escapan a las tensiones políticas e ideológicas que los lugares de memoria revisten. Qué se narra y cómo se narra, así como qué se deja de lado, genera tensiones por parte de los diferentes sectores de la sociedad, quienes pueden sentirse relegados en el relato que se está construyendo. La construcción de los relatos y guiones museológicos no es un ejercicio inocente y neutral, sino que por el contrario tiene unas cargas políticas, simbólicas e ideológicas que corresponden a lo que se quiere recordar y lo que se quiere olvidar.

Otro elemento de tensión y disputa que han traído consigo los museos o centros de la memoria en diferentes partes del mundo es su ubicación en espacios que otrora funcionaron como centros de detención, tortura o aniquilamiento físico. Antiguos campos de concentración, centros de detención o cárceles están siendo acondicionados como equipamientos culturales en los que se busca trasmitir lecturas de lo que pasó desde la mirada de las víctimas y sobrevivientes. Estos nuevos usos que se le han dado a estos espacios han sido un paso adelante en el esclarecimiento de la verdad por 
parte de las víctimas de dictaduras, regímenes políticos o genocidios y, por tanto, motivo de tensiones entre militares y sectores retardatarios que buscan solapar lo que realmente ocurrió.

Yaneth Mora Hernández |

En América Latina, los museos y centros de la memoria están asociados a las fuertes dictaduras militares y conflictos armados que azotaron el continente en el último cuarto del siglo XX. Chile y Argentina fueron los países pioneros en plantear políticas de la memoria y, por tanto, instutuyeron lugares de rememoración que en muchas circunstancias corresponden a los lugares donde ocurrieron acontecimientos o prácticas represivas del pasado reciente — campos de detención, lugares donde ocurrieron matanzas, edificios donde actores sociopolíticos del pasado fueron reprimidos-.

Estos espacios se han convertido en lugares de luchas entre quienes intentan transformar su uso y de esa manera borrar las marcas identificatorias que revelan ese pasado, y otros actores sociales que promueven iniciativas para establecer inscripciones o marcas que los conviertan en "vehículos" de memorias, es decir, en lugares cargados de sentidos (Jelin y Langland, 2003). Villa Grimaldi, transformada en el Parque de la Paz en Santiago de Chile, el Museo de la Memoria y la ESMA (Escuela de Mecánica de la Armada), estos últimos en Argentina, son ejemplos claros de este tipo de lugares de memoria.

En Colombia, en los últimos años se han planteado algunas iniciativas de centros de memoria en ciudades como Bogotá y Medellín que responden a una serie de debates y discusiones alrededor de la problematización de la memoria, sus tensiones y puestas en escena. El Centro de Memoria, Paz y Reconciliación en Bogotá es una apuesta de la administración distrital por territorializar estos debates y discusiones llevándolos a un espacio físico que permita potenciar esta tarea.

\section{Parque por la Paz y Museo de Villa Grimaldi (Chile)}

El Parque por la Paz y Museo de Villa Grimaldi, situado en Santiago de Chile, transformó un ex centro de tortura y detención en un espacio para la reflexión y de actividades que procuran aprender del pasado. Además del parque, el Museo de Villa Grimaldi es una iniciativa que ha venido ampliando y profundizando el trabajo de memoria desarrollado en el Parque por la Paz.

Desde su inauguración en 1997, el Parque se ha transformado en un espacio de reparación simbólica en el cual se desarrollan acciones conmemorativas junto a otro tipo de actividades que permiten a las víctimas de violaciones a los derechos humanos contar con un lugar para el recuerdo y la reflexión.

El fin del Parque por la Paz ha sido contribuir a la promoción de los derechos humanos a partir de las memorias vinculadas a las vulneraciones ocurridas en Villa Grimaldi, ex Cuartel Terranova, el cual funcionó como centro de detención, tortura y desaparición de la dictadura militar llevada a cabo desde 1973 hasta 1990 en Chile.

Para el desarrollo de la colección y exhibición del museo se tomaron los testimonios de personas que permitieron reconstruir la historia de Villa Grimaldi como centro de detención. Se realizó un trabajo conjunto entre el Museo y el Archivo Oral de Villa Grimaldi, fortaleciéndo el trabajo pedagógico dirigido a las nuevas generaciones. Para esto se estructuró un programa educativo asociado a contenidos, actividades y recursos que permitieran realizar actividades con profesores y estudiantes en instalaciones especialmente acondicionadas para ello. 
Además de la visita de jóvenes y escolares, el museo ha buscado convocar a sectores de la sociedad chilena que se han mantenido indiferentes o ajenos a las violaciones a los derechos humanos cometidas por la dictadura, aportando experiencias que promuevan la reflexión sobre el pasado y el presente.

\section{Museos de la memoria en Argentina: resignificación de antiguos centros de detención}

En Argentina, dos escenarios que simbolizan las tensiones políticas e ideológicas alrededor de los usos dados a espacios que en su momento sirvieron como centros de reclusión son el Museo de la Memoria de Rosario y la ESMA (Escuela de Mecánica de la Armada) en Buenos Aires. Estos dos centros corresponden a este tipo de espacios de memoria que como Villa Grimaldi, en Chile, se implementaron en edificios ocupados en el pasado por las fuerzas represoras de la dictadura. El uso dado a estos centros culturales ha sido posible gracias a la labor colectiva y decidida de defensores de derechos humanos, familiares de víctimas y gobiernos de avanzada, quienes en un trabajo conjunto han logrado generar espacios de memoria con un gran sentido de participación.

El Museo de la Memoria de Rosario fue creado en 1998 con el objetivo de promover el acceso al conocimiento y la investigación sobre la situación de los derechos humanos y la memoria social y política en Argentina. Ubicado a doscientos metros del ex centro clandestino de detención conocido como Servicio de Informaciones, este fue un lugar de reclusión, tortura, muerte y desaparición de miles de hombres y mujeres durante la última dictadura. Así mismo, este edificio fue sitio obligado de peregrinación de familiares de detenidos desaparecidos, quienes llegaban hasta sus puertas con la esperanza de obtener alguna respuesta acerca de la suerte corrida por sus seres queridos.

En la estructuración de su guión museológico, el Museo de la Memoria convocó a algunos de los más reconocidos artistas de Rosario para intervenir el espacio museístico alrededor de ejes temáticos que permitieran narrar qué había pasado, convirtiendo este espacio en un escenario de reflexión permanente.

\section{FIGURA 1. MUSEO DE LA MEMORIA DE ROSARIO}

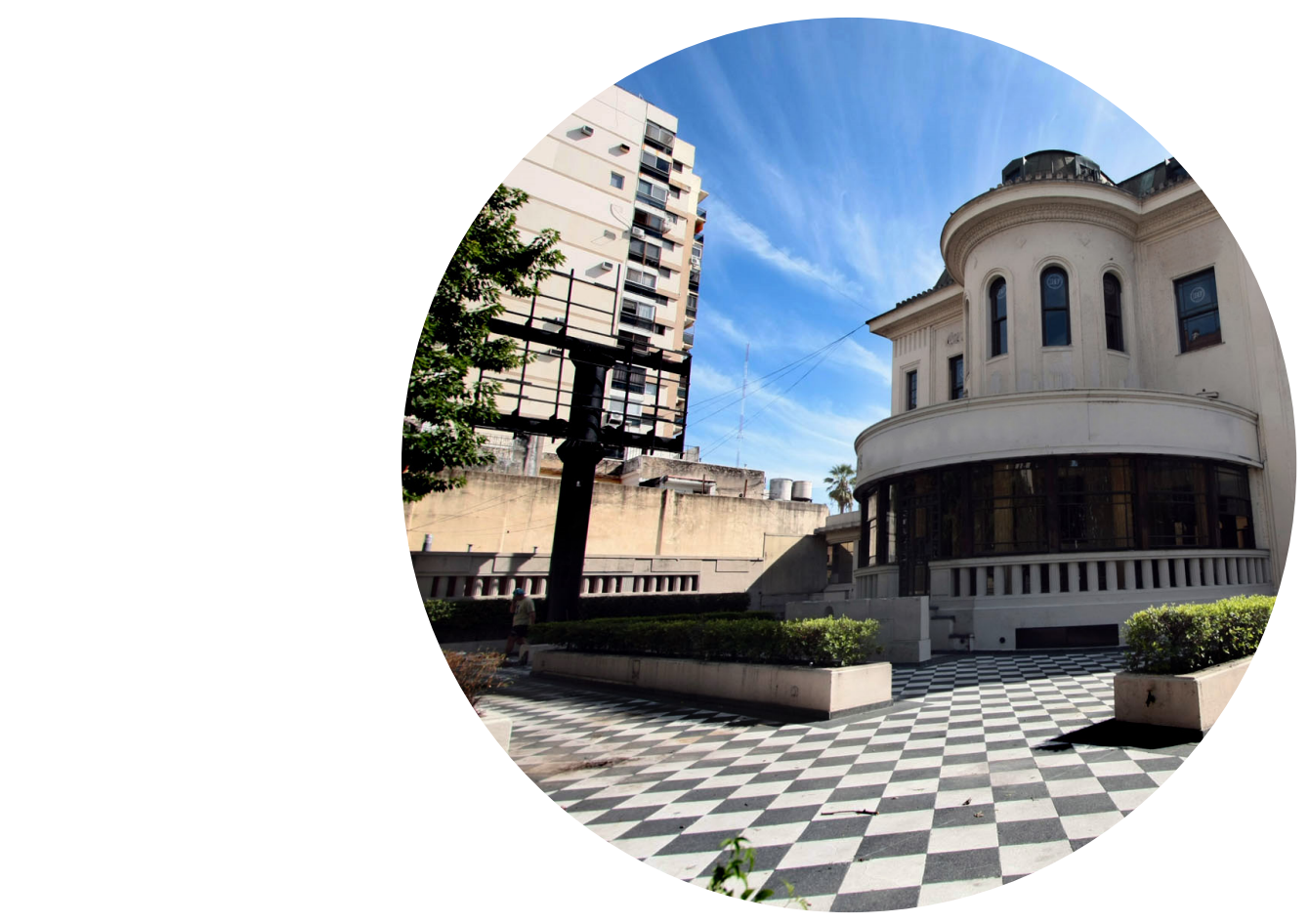

Foto: wwww.memoriaabierta.org.ar 
Yaneth Mora Hernández|
Del mismo modo, la ESMA (Escuela de la Mecánica de la Armada), convertida durante la última dictadura militar en uno de los centros de detención ilegal más importante, actualmente se prepara para convertirse en un equipamiento museístico y cultural. Este espacio sirvió como depósito de tortura y asesinato de miles de ciudadanos considerados como una amenaza para el régimen. Allí fueron trasladados más de 5000 personas, muchas de las cuales fueron finalmente asesinadas (Parsons, 2011).

En el espacio donde ocurrieron estos hechos, y luego de múltiples tensiones entre víctimas, victimarios y Estado, se ha venido impulsando la creación de un lugar de memoria que dé cuenta de lo ocurrido durante este período de violencia política y terrorismo de Estado. Gracias al trabajo organizado de grupos de derechos humanos, en el espacio que otrora generó miedo y represión se ha venido buscando la creación de un lugar de aprendizaje abierto a la reflexión sobre lo ocurrido en el pasado y a la búsqueda de la no repetición.

Desde 1999, y luego de un proceso en el que militares, Estado y organizaciones de derechos humanos entraron en disputa por los usos que se le debía dar al espacio, se han organizado seminarios y talleres de entrenamiento con especialistas locales y extranjeros con el fin de profundizar y desarrollar el debate público acerca del futuro museo.

Este espacio museal buscará que ciudadanos del presente y de las futuras generaciones conozcan la historia reciente mediante testimonios, documentos y objetos. Se busca contribuir a la comprensión de los acontecimientos de las décadas pasadas, estimulando en quienes lo visiten un compromiso activo en la solución de los problemas del país. Para esto, diversas organizaciones de derechos humanos han venido trabajando para reunir, organizar y preservar todo tipo de registro que pueda constituirse en patrimonio del futuro museo.

Tanto para los supervivientes como para los familiares de los desaparecidos, la presencia de este tipo de museos es un medio de conservar y gestionar las memorias del pasado. Por medio de este tipo de escenarios estos grupos pueden desarrollar una narrativa que rinda homenaje a sus familiares y que, al mismo tiempo, concientice a la sociedad acerca de las violaciones de los derechos humanos cometidas en Argentina durante sus dictaduras militares.

\section{FIGURA 2. ESMA (ESCUELA DE LA MECÁNICA DE LA ARMADA)}

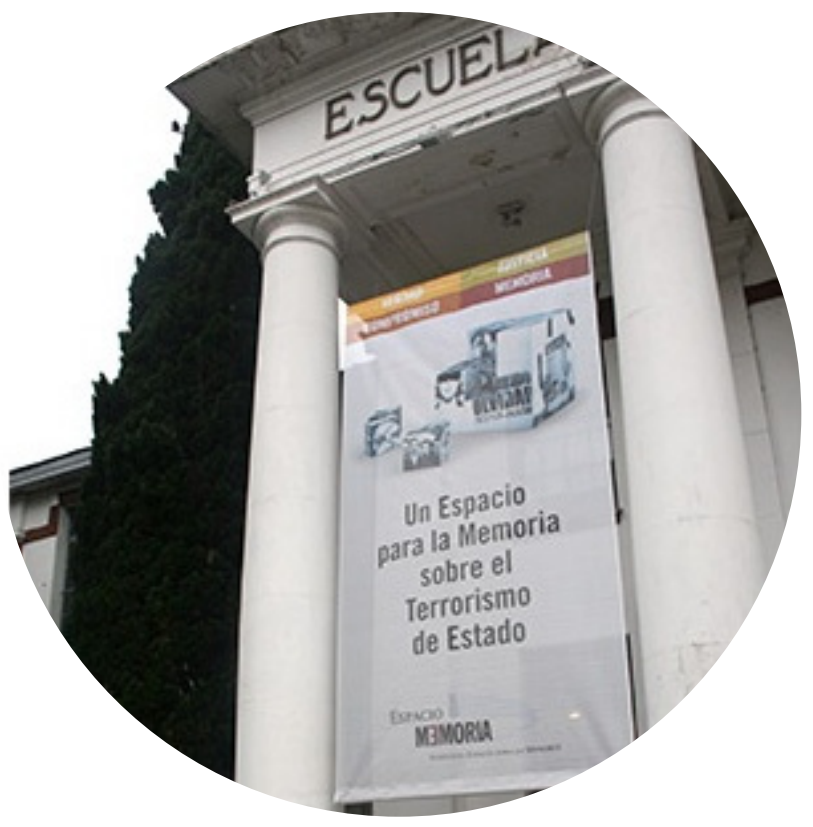


En Colombia, los debates y discusiones alrededor de la memoria se desarrollan en un escenario particular de conflicto permanente, situación que ha hecho difícil un diálogo en condiciones de igualdad o con la tranquilidad que proporciona el fin de la confrontación. Esta situación ha generado una serie de dificultades y singularidades a la hora de hablar de memoria y de sus procesos de territorialización en espacios públicos.

Aun así, y en medio de un contexto diferente a los escenarios ya descritos, han surgido iniciativas desde diferentes escenarios (oficiales y no oficiales) que han permitido que las discusiones alrededor de la memoria irrumpan y generen importantes iniciativas. Una de estas iniciativas desarrollada desde instancias del gobierno distrital ha sido el Centro de Memoria, Paz y Reconciliación de Bogotá. Este espacio ha sido planteado como un escenario para la promoción de ejercicios de memoria histórica colectiva que permitan el reconocimiento de los derechos de las víctimas del conflicto y la construcción de paz, impulsando una cultura de democracia y garantía de los derechos humanos.

Este centro ha sido diseñado como un espacio público abierto a toda la ciudadanía para incentivar la comprensión de las causas y consecuencias de la violencia política y del conflicto armado en Colombia, desde mediados del siglo $\mathrm{XX}$, así como de sus expresiones en Bogotá y en la región central. Esta obra es un reconocimiento a las víctimas y a la búsqueda de la paz y la no violencia en la región capital y en Colombia con el que se busca que se discutan y analicen las condiciones para la construcción de verdaderos criterios de paz en el país, condiciones que están afincadas en la memoria y la reconciliación.

Este espacio ha venido buscando y permitiendo la articulación de las diversas iniciativas de memoria mediante la participación en investigación, pedagogía, comunicación, artes y otras formas de acción transformadora desde la ciudadanía, las organizaciones sociales, los centros académicos y culturales y las instituciones distritales. Se busca que la construcción de memorias sea un proceso plural, participativo, y que vincule a quienes desde diferentes expresiones están pensando en la construcción de una sociedad en paz e incluyente. En este espacio se busca promover una cultura de no violencia activa, una cultura ciudadana por la verdad, la justicia y la reparación, así como apoyar la formulación de propuestas y políticas de reparación moral, simbólica, psicológica, colectiva, trabajando de la mano con la academia y toda la ciudadanía (Romero, 2012).

El memorial y el centro están emplazados en el Parque de la Reconciliación y la Memoria Histórica, tal como lo determinó el Concejo de Bogotá en el Acuerdo 174 de 2005. Su construcción se inició después de concluido un trabajo minucioso y respetuoso de antropología forense que permitió el hallazgo de alrededor de 3600 individuos en la zona que correspondía a un cementerio destinado a los pobres de Bogotá, en el costado occidental del Cementerio Central de Bogotá.

Tanto el memorial como el centro están cargados de un gran simbolismo que busca sensibilizar y comunicar a la ciudadanía la importancia de la memoria en la construcción de la paz. El memorial por la paz y los derechos humanos de 18 metros de altura, en cuyas paredes exteriores hay un centenar de ventanas, simboliza el bicentenario de la independencia nacional, el dolor por las víctimas y la luz que reivindica la verdad. Así mismo, la campaña "Tierra Sembrada de Memoria” fue una iniciativa con la que se buscó la participación colectiva de organizaciones de víctimas y defensores de derechos humanos en la construcción del centro. Con esta campaña se buscó construir este espacio a partir de los aportes de tierra, para rendir un homenaje simbólico a las víctimas, expresar su solidaridad y dejar un testimonio colectivo por la dignidad.

Ahora bien, los desafíos del Centro de Memoria, Paz y Reconciliación son enormes, dado que Colombia es un país donde el prolongado y ondeante conflicto social y armado genera cada día nuevas tensiones. Aun así, la importante participación colectiva de familiares de víctimas, grupos de derechos humanos y demás sectores sociales puede generar

| Panorama | pp. 97 - 109 | Volumen 7 | Número 13 | Julio - diciembre | 2013 | 105 
un escenario que permita avanzar en la consecución de una cultura política donde las memorias emerjan y sea posible la búsqueda de la verdad.

\section{MONUMENTOS CONMEMORATIVOS: MÁS QUE MOLES DE CEMENTO}

Yaneth Mora Hernández|

Los monumentos conmemorativos también corresponden a lugares de memoria territorializados que buscan constituirse en espacios de reflexión crítica alrededor del pasado reciente. Estos lugares se han erigido en diferentes lugares del mundo como parte del proceso de reconciliación y reparación moral que siguió al fin de experiencias de conflicto armado, genocidio y dictaduras militares. La ocupación de los espacios públicos por parte de estos monumentos conmemorativos supone una transformación del paisaje urbano mediante la cual se invita a observar, a leer, a tocar, a formar parte de la instalación, para que el visitante se interese en conocer el porqué de su existencia.

Estos espacios rinden homenaje a los muertos del conflicto armado, a los desaparecidos y en general a las víctimas, como una forma simbólica de mantener viva su memoria. Aun cuando dichos espacios no reemplazan la búsqueda de verdad, justicia y reparación, su construcción ha venido desempeñando un papel importante en el acompañamiento de estas demandas de las víctimas, erigiéndose como una forma de reparación moral.

Los monumentos conmemorativos ubicados en el espacio público reflejan los imaginarios sociales que existen sobre dicho espacio, proyectando las valoraciones e interpretaciones que sobre la memoria social han hecho colectivos humanos. Al igual que los centros o museos de la memoria, los monumentos conmemorativos no escapan a las tensiones y conflictos. En su modo de desplegarse en el espacio puede detectarse el grado de consenso o conflicto que subyace a los relatos sobre el pasado, así como las tensiones que atraviesan el presente (Schindel, 2009).

Dentro de las tensiones que subyacen a los monumentos conmemorativos se evidencia si estos espacios pueden realmente comunicar de una manera dinámica y viva la memoria del pasado reciente, y por lo tanto promover diálogos intergeneracionales, interrogar activamente o formular nuevas interpretaciones sobre lo ocurrido, o si por el contrario su condición estática no permite este tipo de dinámicas.

La crítica que el sector más radical de las Madres de Plaza de Mayo ha hecho a los monumentos incrustados en el espacio público nos ofrece un ejemplo de lo anterior. Ellas se oponen radicalmente a toda forma de homenaje que implique listas con nombres, placas o flores, pues creen que esto equivaldría a equiparar a un desaparecido con un muerto. Creen en cambio que la memoria se ejerce recreando los ideales que animaron a la mayoría de los jóvenes "desaparecidos", y en lugar de sitios fijos de memoria, como monumentos, han fundado sitios de encuentro tales como un café o un centro cultural (Schindel, 2009).

Ahora bien, si indudablemente la construcción de monumentos conmemorativos reviste tensiones por parte de diferentes actores sociales, es una iniciativa que representa la lucha por la democracia y los derechos humanos. Su erección en el espacio urbano es un avance significativo en la búsqueda de reivindicar la memoria y establecer iniciativas que resignifiquen lugares con valor simbólico y político. Las luchas por la memoria se ven representadas en este tipo de monumentos, que simbolizan que no todo está escrito y que es importante recordar, para que las nuevas generaciones no caigan en los mismos errores.

Número 13 |

Parque de la Memoria-Monumento a las Víctimas del Terrorismo de Estado y memorial de recordación de los detenidos desaparecidos

En diferentes partes del mundo los monumentos conmemorativos han sido parte del proceso de territorialización de la memoria, estos se ubican en el espacio público y generan procesos de reflexión. En Buenos Aires, Argentina, un ejemplo interesante lo constituye el Parque de la Memoria-Monumento a las Víctimas del Terrorismo de Estado, 
un espacio de conmemoración fruto de una experiencia conjunta entre organizaciones civiles y el Estado. Este monumento, ubicado de manera simbólica frente al Río de la Plata, ya que a sus aguas fueron arrojadas muchas de las víctimas de la dictadura, es un lugar de recuerdo y testimonio. Sus impulsores destacaron desde el comienzo que la obra no reemplazaría los reclamos de verdad y justicia por los crímenes de la dictadura y que la figura del desaparecido debía mantener su condición irresuelta.

Este monumento fue trazado como una herida abierta en la tierra y se compone de cuatro estelas de hormigón que contienen 30.000 placas, de las cuales cerca de 9.000 se encuentran grabadas con los nombres de hombres, mujeres y niños víctimas del terrorismo de Estado. Con este diseño de corte en el terreno, el monumento simboliza la herida que dejó en la sociedad la violencia ejercida durante la dictadura militar y, sin pretender cerrarla, se constituye como un espacio de reflexión y de recuerdo para cada una de las personas en él incluidas.

Los nombres comprendidos en el monumento se encuentran colocados por año de desaparición o asesinato y, dentro de cada año, guardan un orden alfabético. De cada persona incluida, esta lista se colocó también la edad y se señalaron los casos de mujeres que se encontraban embarazadas.

El monumento cuenta con un programa educativo para grupos escolares de diferentes niveles de formación que comprende visitas guiadas, rutas de interpretación, capacitaciones y materiales educativos para docentes. Con este programa se busca hacer del monumento un espacio vivo de aprendizaje y constante sensibilización y reflexión alrededor de la construcción de memorias.

Del mismo modo, en Uruguay, el Memorial de Recordación de los Detenidos Desaparecidos es un espacio de memoria enclavado en el espacio público con el que se busca avanzar en la reparación simbólica a las víctimas y familiares de los miles de desaparecidos de la dictadura militar. Al igual que en Argentina, este monumento conmemorativo surgió por el esfuerzo combinado de actores de la sociedad civil y del Estado mediante una comisión mixta.

Construido sobre un sitio de alto simbolismo como el cerro de Montevideo, se originó en 1998 como proyecto conjunto de la Intendencia de Montevideo y las madres y familiares de detenidos desaparecidos. Fue diseñado con la intención de aprovechar el carácter agreste del parque donde está ubicado y hacer dialogar a la obra con el paisaje. Se trata de un cuadrado trazado en un claro del bosque del cual se retiró la primera capa de terreno hasta llegar a la roca viva, dejada a la intemperie como símbolo de la verdad desnuda. Dos muros de vidrio con los nombres de los desaparecidos esmerilados penetran en la roca creando entre ellos un espacio de recogimiento en plena intemperie. Los nombres de los desaparecidos uruguayos parecen estar suspendidos sobre el paisaje evocando la condición abierta de los desaparecidos, mientras el cristal sugiere la fragilidad de la vida. El monumento se integra con la naturaleza a través de la roca, que forma parte del monumento, pero interrumpe a la vez la continuidad del paisaje.

\section{FIGURA 3. MEMORIAL DE RECORDACIÓN DE LOS DETENIDOS DESAPARECIDOS EN URUGUAY}

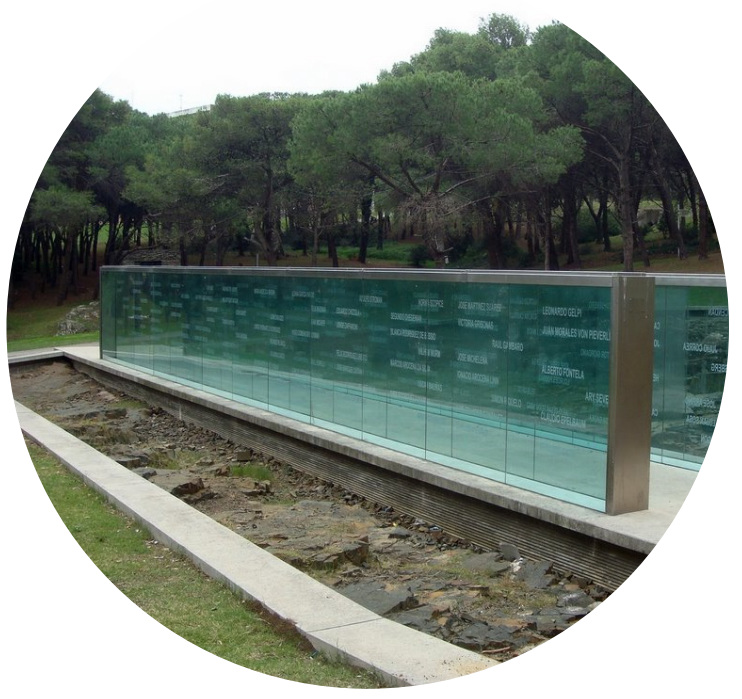




\section{CONCLUSIONES}

En las sociedades contemporáneas los lugares de memoria se han constituido en escenarios de reflexión sobre los errores del pasado, los desafíos del presente y las lecciones para el futuro. Muchos de estos lugares de memoria, además de la labor restitutoria y simbólica para las víctimas y sus familiares, se han convertido en escenarios educativos y culturales donde niños, jóvenes y adultos consiguen encontrarse y dialogar sobre lo que no puede volver a ocurrir.

Los lugares de memoria (museos y monumentos conmemorativos) se han logrado establecer a partir de una lucha sistemática, organizada y constante de organizaciones de víctimas y grupos de derechos humanos, quienes a partir de una labor por la búsqueda de la verdad y la justicia han conseguido impulsar políticas de la memoria. Dichas políticas han logrado procesos de reconstrucción de la verdad y levantamiento de lugares simbólicos con los que se territorializan las memorias colectivas y se erigen espacios educativos de reflexión. Sin la lucha de estas organizaciones, los lugares de memoria no tendrían lugar, ni tampoco los procesos de construcción de ciudadanía que dichos espacios generan.

Ahora bien, al ser una construcción colectiva, intersubjetiva y social, la memoria supone una serie de tensiones políticas e ideológicas de las que los espacios de memoria no escapan. Las tensiones políticas e ideológicas que revisten estos lugares afloran por las posiciones encontradas de quienes pugnan por la verdad y la justicia, por un lado, y quienes quieren ocultarla, por otro. La gestión de una memoria colectiva atravesada por este tipo de conflictos políticos está caracterizada por los deseos de recordar y olvidar, y es justamente esta dicotomía entre lo que se recuerda y se olvida, manifiesta en los lugares de memoria, lo que está siendo constantemente objeto de disputas y tensiones. Qué recordar y qué olvidar y cómo representarlo en el espacio público ha sido y seguirá siendo objeto de luchas ideológicas y políticas en las que museos y espacios conmemorativos desempeñan un papel fundamental. 
1. Brett, S.; Bickford, L.; Ševcenko, L. y Ríos, M. (2009). Memorialización y democracia. Políticas de Estado y acción civil. Santiago, Chile: Flacso.

2. Escobar. C.y Fabri, S. (2009). Memoria y espacio social. La territorialización de la memoria en la construcción de ciudadanía [documento inédito]. Buenos Aires, Argentina.

3. Guixé,J. (2009). Espacios, memoria y territorio: un memorial en red en Cataluña. En R.Vinyes (ed.), El Estado y la memoria. Gobiernos y ciudadanos frente a los traumas de la historia. Barcelona, España: RBA.

4. Jelin, E. (2001). Los trabajos de la memoria. Madrid, España: Siglo Veintiuno.

5. Jelin, E.y Langland, V. (2003). Las marcas territoriales como nexo entre el pasado y el presente. En E. Jelin (ed.), Monumentos, memoriales y marcas territoriales (pp. 5-11). Madrid, España: Siglo Veintiuno.

6. Loreto, F.y López, G. (2005). Entre el recuerdo y el olvido. Revista Patrimonio Cultural 10 (37), 12-21.

7. Nora, P. (2009). Pierre Nora en Les Lieux de Mémoire. Santiago, Chile: LOM.

8. Parsons, E. E. (2011). Espacio para el recuerdo: memoria colectiva y reconfiguración del disputado espacio de la ESMA de Argentina [artículo en línea], 452 ${ }^{\circ} \mathrm{F}$. Revista Electrónica de Teoría de la Literatura y Literatura Comparada, 4, 29-51. Recuperado de en: http://www.452f.com/pdf/numero04/ parsons/04_452f_mono_parsons_trad_es.pdf

9. Romero, R. (2012). Centro de memoria, paz y reconciliación [documento inédito]. Bogotá, Colombia.

10. Schindel, E. (2009). Inscribir el pasado en el presente: memoria y espacio urbano. Política y Cultura, 31, 65-87.

11. http://www.sitesofconscience.org/es/

12. http://villagrimaldi.cl/

13. http://www.museodelamemoria.gob.ar/

14. http://www.memoriaabierta.org.ar

15. http://www.parquedelamemoria.org.ar/ 